\section{Treating Netwooks Seriously: Practical and Research-Based Agendas in Public Administration}

Laurence J. O'Toole, Jr., The University of Georgia

How well equipped are today's public administrators to face the challenges they confront from the involvement of businesses, notfor-profits, other units of government, and even clients in complex patterns of program operations? Not very well, if judged by the extent to which practitioners and scholars have incorporated the network concept and its implications into their own work. Discussions in the field contain little to help practicing managers cope with network settings. In fact, conventional theory may actually be counterproductive when applied inappropriately to network contexts. And yet, these arrays are now consequential and becoming increasingly so. Practitioners need to begin to incorporate the network concept into their administrative efforts. The challenge for scholars is to conduct research that illuminates this neglected aspect of contemporary administration. The author sketches a set of agendas that offer prospects for helping to address this need.
Public administration ${ }^{1}$ increasingly takes place in settings of networked actors who necessarily rely on each other and cannot compel compliance on the part of the rest. Yet the standard writings to which most administrators turn for advice to improve performance devote relatively little attention to acting effectively in such situations. (Examples include Hill, 1992; Levine, Peters, and Thompson, 1990; and Wamsley et al., 1990.)

Networks are structures of interdependence involving multiple organizations or parts thereof, where one unit is not merely the formal subordinate of the others in some larger hierarchical arrangement. Networks exhibit some structural stability but extend beyond formally established linkages and policylegitimated ties. The notion of network excludes mere formal hierarchies and perfect markets, but it includes a very wide range of structures in between. The institutional glue congealing networked ties may include authority bonds, exchange relations, and coalitions based on common interest, all within a single multiunit structure. In networks, administrators cannot be expected to exercise decisive leverage by virtue of their formal position. Influence in larger networks is more difficult to document, predict, and model than it is in relatively simple two- or threeparty relationships.

Scholarly work on public administration has proceeded for decades from the seminal contributions of Herbert Simon (1976) and others, who argued that hierarchy can "push back" the decision-making weaknesses experienced by individuals - converting their human limitations (like selective perception) into organizational strengths. This result is not inevitable, and it is the challenge of the manager to craft the contexts in which others must make decisions so that they will have what they need to make sound choices efficiently. 
Part of the task is arranging the hierarchy so that each subunit can pay attention to itself and its near neighbors while largely ignoring the rest of the world, even the rest of the organization. "Near decomposability," which hierarchy permits, works (for Simon) because of an assumption about the world in which organizations operate: that complex tasks can usually be divided up into small, relatively independent components that can be treated separately while still contributing to the overall objective (1976, 69). Later theorists noted that this assumption is probably too strong. Certainly hierarchy can bring some efficiency advantages even if the strict assumption does not hold. ${ }^{2}$

If, however, the issues with which public managers are being asked to deal are increasingly what Rittel and Webber (1973) have called "wicked problems"-challenges that cannot be handled by dividing them up into simple pieces in near isolation from each other-then alternative forms of organizing must be more suitable. No clearly appropriate organizational form, or set of forms, has attracted general support. Matrix organizations, flexible work groups, and interagency coordinating committees are all structural responses to certain forms of "wickedness." But there is no comprehensive theory to suggest how to manage such organized effort. ${ }^{3}$ To the extent that public problems have acquired characteristics of wickedness, this article suggests that administrators are now either operating with inappropriate organizational models or adapting conventional structures to meet the more challenging demands. Versions of network development may be underway. What does the evidence suggest?

\section{Why Treat Networks Seriously? Some Evidence}

The data regarding the importance of networked action in public administration are not conclusive. Most of the evidence is indirect; however, if it indicates trends, it is fairly convincing. Furthermore, as demonstrated in the next section, the kinds of forces currently encouraging the expansion and proliferation of networks range far beyond those typically sketched by economists or organization theorists.

Kettl points out that direct federal spending for single-agency program operations accounts for a small slice of the huge national budget (1993, 61-62). At other levels of government, even with cutbacks in federal aid, intergovernmental programs make up a sizeable proportion of the total. This conclusion is especially clear when one counts state, local, interlocal, interstate, and nongrant efforts - including intergovernmental regulation. What is omitted by these measures is a congeries of programs involving more subtle arrays. "In addition to the huge role that state and local governments play in the 'Washington bureaucracy,' almost every major federal domestic policy directly involves either private contractors, or non-profit organizations, or both" (Dilulio and Kettl, 1995, 17). It is worthwhile, therefore, to survey a broader range of collaborative efforts.

These efforts encompass several categories. First, governments often seek to execute their efforts via structures of interagency collaboration. Second, the role of not-for-profit organizations is large and growing. Third, the frequency and variety of links with forprofit firms is impressive, and government contracting remains a
Pressures to offload direct service provision while

also assuming policy responsibility catalyze further

networking through more complex patterns that aim at

\section{splitting or sharing labor and responsibility.}

growth industry. More thoroughgoing forms of privatization are commonplace, despite the periodic exposé, scandal, and disappointment. Public-private partnerships vary in several respects, but they typically involve government and profit-driven interests joined to increase the scale and visibility of program efforts, to increase support for projects, and to leverage capital to enhance feasibility, speed, or effectiveness. Indeed, they often involve not merely one private organization but a range of them. Many forms of entrepreneurial government effort touted by Osborne and Gaebler (1992) involve forms of networking not adequately captured in aggregate data on intergovernmental programs and contracting.

The extent of interunit patterns is considerable. Such structures often involve webs of public, not-for-profit, and business organizations in crosscutting configurations. Even at the international level, agreements on issues such as environmental quality have been translated into policy in many nations, and domestic program managers find themselves linked in multilevel and cross-national webs "from the negotiating table to the shop floor" (Hanf, 1994).

Recent trends, including privatization, reinvention, budget cutting, and initiatives from the Republican Congress, are unlikely to stop or appreciably slow the phenomenon. Pressures to offload direct service provision while also assuming policy responsibility catalyze further networking through more complex patterns that aim at splitting or sharing labor and responsibility. This point is obvious when considered in the context of some recent policy initiatives, such as the proposals for reforming U.S. health care. Sometimes overlooked, however, are less-conspicuous instances such as the role played by intermediary institutions in service provision networks for any voucher-style policy initiative.

\section{The Growing Importance of Networks}

A contestable thesis can be suggested: Complex networks are not only relatively common, they are also likely to increase in number and importance. Why? The discussion of wicked policy problems suggests one reason, and additional forces seem to be at work as well. Policies dealing with ambitious or complex issues are likely to require networked structures for execution, and complex issues will continue to be on the policy agenda. Indeed, and this point can be considered a second influence, the limitations often established on the reach of direct governmental intervention encourage rather than dampen networked approaches. Preferences for limited, liberal government in the context of widespread support for action encourage complex, networked mechanisms for service delivery and management-extending the reach of government programs while loosening the immediate managerial grasp. Setting ambitious objectives in contexts of dispersed power makes networking imperative for program managers. 
Despite contrary sentiments and certain efforts to unwind the network spring, the emergence of networks in

\section{public management is not a passing fad.}

Third, political imperatives elicit networking beyond what might be necessitated by policy objectives. This venerable point is hammered home in numerous studies of individual programs (see the classic treatment in Pressman and Wildavsky, 1984). Legislative coalition building has its administrative counterpart as managers and others begin the arduous process of execution. Administrators often must balance technical needs for clear and concentrated program authority with political demands for inclusion and broader influence.

Fourth, as information has accumulated regarding second-order program effects, efforts have been made to institutionalize the connections. Witness the growth of interagency committees and advisory commissions (Light, 1995). Fifth, layers of mandates constitute another pressure for networked management. Instruments such as crosscutting regulations (applied to many programs, like civil rights or environmental rules) and crossover sanctions (penalties in one field for compliance failures in another) escalate coordination requirements. Transportation program managers cope with the rights of the disabled, protection of endangered species, and energy conservation, not simply transportation efficiency and effectiveness, multimodal balance, and land use. An inevitable consequence is the development of networked connections.

Related trends also operate within a policy field. In dense policy spaces like housing or economic development or welfare, different programs have different intents, funding sources and priorities, mandated criteria, and targeted stakeholders. (Policy spaces are dense when a number of initiatives occupy a given sector of governmental effort.) Achieving something meaningful in any one program must mean adapting to several.

For all these reasons, it is reasonable to expect an increase in public administrative networking. Milward and Provan (1993) have used the evocative and vaguely threatening image of the "hollow state" to characterize what they regard as the increasingly networked character of public management (see also Milward, 1996). They argue that practitioners in the coming years will face fundamental challenges to achieving the traditionally important norms of efficiency, effectiveness, responsiveness, and accountability.

The case for a networked future should not be made too strongly. Some forms of policy change, such as initiatives to "hive off" public institutions or sell large quantities of public assets in the market, would signal a form of simplification. Similarly, administrative reorganizations could reduce cross-institutional interdependence for selected policy sectors. It is possible though perhaps not likely that some current reforms such as the Unfunded Mandate Control Act of 1995 may slow the growth substantially.

Despite contrary sentiments and certain efforts to unwind the network spring, the emergence of networks in public management is not a passing fad. Data suggest that these arrays have expanded beyond the small clusters that have been the focus of discussion in intergovernmental management and contract administration. Sev- eral influences appear to be at work to encourage further expansion. For all this admittedly spotty evidence, there has been relatively little impact on scholarship in the field. The dominant picture, as seen in courses, texts, and standard theories, is that of a universe centered around the individual agency and its management. Accordingly, there is plenty of work to be done to adapt what we think we know to the emerging networked world.

\section{Practical and Research-Based Agendas}

Treating networks seriously has not been a priority in the world of public administration. Still, the theme has not been ignored altogether. ${ }^{4}$ Some administrators have noted the prominence of networks in their operating setting and have begun to consider implications for practice. Researchers, too, have started to devote effort to topics that can enhance scholarly understanding of networks and public management.

What implications follow from a recognition of the importance of networks to the conduct of public administration? The coverage below addresses a portion of the agendas for the field.

\section{The Practical Agenda}

Ultimately, the most important question regarding networks and public administration is the pragmatic one: So what? What difference does it make in practice if administrators are situated in complex structures of networked interdependence? The answer is not obvious. Important parts of the response must be informed by research that is only just beginning. However, just as the assumption of formal hierarchy provided clues regarding how to manage in an earlier era, the distinctive features of network structures offer some very preliminary hints for practice.

First, standard nostrums of public administration probably do not apply. Managers in networked settings do not supervise most of those on whom their own performance relies, monitoring channels are typically diffuse and unreliable, and common organizational culture exercises a limited and indirect influence. In network arrays, several sets of organizational needs must somehow be incorporated into streams of action without compromising programs to the point of incoherence. Perhaps most important, networks themselves are sufficiently complex that their impact on performance is somewhat unpredictable for all involved. Managing in this world implies significant adjustment of the conventional wisdom. Indeed, the very notion of management may have to be modified. Needed forms of management may be counterintuitive. That is, action guided by the hierarchy assumption is likely to lead not just to ineffectual but to counterproductive outcomes.

The injunction is not merely to learn bargaining skills. In the world of networks, the results of dyadic negotiations (between public organization and its contracted agent, for instance) may be decisively influenced by background or default conditions established through decisions among parties elsewhere in the network (a social services coordinating council, a consolidation among private firms in the service-provision sector).

The practical agenda would seem to include, then, the following points as first steps for public administrators operating in a networked world: 
1. Administrators should not assume that they possess authority; giving directives may actually weaken influence.

2. Administrators should conduct regular self-surveys of their network(s) to make a rough inventory of their principal contingencies and alliances. They need to be alert to the fact that their networks may extend beyond the set of immediate interaction partners. For network surveillance, administrators should support boundary-spanning units, which can be among the first to be cut in tough times.

3. Administrators should look for opportunities to identify coordination points for the full set of actors in the network: common ground, practices, or procedures that serve most interests represented in the array.

4. Administrators should consider two additional lines of potential influence:

a. Act within the network to move the cluster of actors toward cooperation in the interests of program success. Use information to heighten the salience of preferred choices; convey knowledge about how cooperation can serve interests of the others; honor confidences; and focus participants' perceptions on elements crucial for success. Network management involves trying to build trust among the participating parties (O’Toole, 1995).

b. Act to alter the network structure toward a more favorable array. The influence of such structures on program outcomes is not well understood. However, some obvious points can be used: find ways to shift network membership toward more supportive coalitions; locate key allies at crucial nodes; try to alter agreements among the parties to heighten program salience; and buffer well-functioning arrays to limit uncertainty and complexity.

How to turn network knowledge, as it develops, into practical, useful information is the nub of the issue. Preliminary studies have begun to raise the question of management practice in a networked world. For example, Stoker (1991) offers suggestions for practice that run counter to old chestnuts of managerial lore. He argues convincingly that the complexity and uncertainty in networks can present imposing barriers to program success. He believes that one way of lowering these barriers is to use arrays with existing units that share a history of cooperation and some trust, rather than to create new organizations (as is often proposed) that must forge links and develop network understandings from the ground up (see also Mandell, 1990; Agranoff, 1991; O'Toole, 1995).

These contributions are mere beginnings. More useful and extensive practical advice is largely dependent on progress along several related, albeit distinct, lines of research. The most important of these can now be outlined.

\section{The Conceptual and Descriptive Agenda}

For all the evidence that networks are important for public administration, most of the discussion of this subject has been vague. Helpful starts have been made in other fields. In particular, sociologists and public choice specialists have developed rich conceptualizations regarding networks (Cook and Whitmeyer, 1992; Knoke and Kuklinski, 1982; Ostrom, 1990; Parks, 1985). But

\section{For all the evidence that networks are important for}

\section{public administration, most of the discussion of this}

\section{subject has been vague.}

these developments have not penetrated very much of the work being done on public management. A few important exceptions are discussed below.

Beyond these conceptual issues, but closely related to them, lies a set of fundamental descriptive tasks requiring sustained attention. At least three kinds of efforts are warranted: (1) determining what networks, and what kinds of networks, can be found in today's administrative settings; (2) examining the historical dimension of network formation and development; and (3) exploring the array of networks in a broadly comparative perspective.

The first task, describing what is out there in the world of contemporary public administration, is more challenging than may be apparent. The systematic information needed to ascertain the prominence of networks is not now available. Careful accounts of the full array of national programs for their network features and the worlds of most middle managers for network-based behavior, for example, need to be a part of the research agenda. What variations can be documented? What further conceptual development would seem to be suggested? What do these findings mean for managers? What proportions of their time and resources are spent in the network as opposed to the hierarchy? What distinctive tasks does their networking involve?

Second, describing networks in historical terms can offer ideas regarding the causes, as well as consequences, of networks. There has been some disagreement, often implicit, over explanations for the emergence of such structures. European social scientists, in particular, have claimed broadly that increased networking is a consequence of challenges found in "late welfare states" (Scharpf, 1977; Offe, 1984).5 Others claim that networks are not particularly new. Only careful historical research and more contemporary longitudinal studies can hope to shed light on the issue (see Ansell, 1993, for an interesting example).

Finally, most American administrative scholarship has restricted itself to the context of the United States. Comparative investigations, however, are essential for scientific advance (Dahl, 1947). Provocative research on networks is conducted abroad and largely ignored in the U.S. public administration community. German social scientists link networks to welfare state demands. Dutch public policy and management scholars explore questions of "steering" when programs operate in network contexts (Hufen and Ringeling, 1990). British scholars emphasize networks for policymaking and implementation. Other literatures, such as studies of corporatism, also bear on the network agenda. Do national variations in network characteristics signal important features of policy and management processes? Answering such questions requires systematic cross-national inquiry.

\section{The Agenda for Empirical Theory}

If the public administrative world is networked, how does this 


\section{this fact bear on demands, behaviors, and determinants of}

\section{managerial success?}

fact bear on demands, behaviors, and determinants of managerial success? This subject requires a consideration of networks as causal forces in the administrative setting, particularly regarding effects on the traditional concerns of public administration, such as efficiency, effectiveness, equity, responsiveness, and responsibility.

Contributions within Public Administration. Some administrative scholars have been wrestling during the last several years with theoretical questions bearing on networks. Progress has been uneven. The prime initiatives with relevance to public management in networks have been efforts to explore policy implementation, studies using game theory to model networked structures, and some recent investigations of links between network properties and service-delivery outputs.

The field of policy implementation has tended to focus on interorganizational instances, so it is not surprising that its scholars have been grappling with the network issue. Research from the socalled bottom-up perspective has been helpful in emphasizing the importance of networked action and showing that such arrays are not necessarily less effective than unitary institutions. This approach to implementation has been less helpful, however, in the development of empirical theory (Mazmanian and Sabatier, 1990). There have been exceptions (for instance, Hull with Hjern, 1987), but additional work is required.

Some research by implementation theorists and others has focused on game theory for understanding networked settings (Stoker, 1991). Lynn (1993) has used game theory to model multilevel dynamics in social service agencies (see also Koremenos and Lynn, 1996). Unfortunately, it cannot really be said that this approach models networks; Lynn treats occupants of different levels in the same hierarchy as the interdependent players. The approach does include clients, so the analysis demonstrates the potential for larger constellations. However, it might be argued that these models are misspecified in the opposite fashion than is the case for conventional treatments. Most analysts assume that managers occupy rungs in a hierarchical ladder and downplay horizontal ties, whereas Lynn treats vertical interactions as if they consist of bargaining among formal equals, thus ignoring the inherent power differential.

The broader point is that formal models of networked action must combine both the vertical elements of hierarchy and the horizontal components of functionally induced interdependence (O'Toole, 1993). As suggested below, some work based in public choice has also offered ways of approaching the modeling issue, but here, too, the perspective is limited by the omission of any hierarchical component. At a minimum, hierarchies embedded in or complicating the network game might be included by modeling links between the network game and one or more others (the employment game, the promotion game, the agency game) in which superiors hold many more cards than do subordinates.

Despite its weaknesses as an approach, game theory offers advantages aside from rigor. It puts the set of interdependencies in the foreground, not individual actors or organizations. The full constellation of actors, preferences, and structure matters.

This emphasis on the network as a whole also pertains to some recent work offering insightful network analysis. Provan and Milward (1995) provide an example of how theory building for public administration might be guided by the proposition that networks should be taken seriously. They have recently completed an intensive, four-city study of service implementation networks for the severely mentally ill. The arrays consist in each case of many organizations linked in complex, functionally specific patterns. This work marks one of the first efforts to assess network performance and to link performance with structural features of the networks themselves. Network performance is explained here by the degrees and types of integration, external control, stability, and environmental resource munificence of the arrays. Provan and Milward demonstrate that at least in some policy fields, an adequate understanding of administrative performance cannot be achieved without theory building at the network level of analysis.

Contributions from Other Fields. The preceding subsection shows that networks have been treated seriously by some researchers within public administration. But most of the theoretical work has been developed by scholars specializing in other social sciences.

One line of research derives from sociology, where network analysis has been under development. Some efforts have applied such approaches to investigate policy networks (e.g., Pappi, Knoke, and Bisson, 1993), although their use for public administration has yet to emerge. Somewhat more familiar may be the resource dependence/exchange perspective. This work has proven useful for understanding patterns of service provision. More adaptation to the network level and to public administration could prove helpful.

Potentially important theoretical work has been developing from economics as well. One variety is game theory, discussed above. Another is transaction costs economics, which is beginning to receive attention in public administration (Maser, 1986; Thompson, 1993; and Horn, 1995). A third is public choice, where provocative work is being done by scholars like Elinor Ostrom (1990), who has combined a public-choice perspective with the analytical strength of game theory to model nonhierarchical collective action efforts involving multiple actors, diverse arrangements, and varying conditions. She has combined this work with a massive review of evidence regarding common-pool resource management around the world, with the aim of building robust inductive theory. In a complementary effort, she has initiated an experimental project to seek answers to how individuals self-organize to solve collective-action problems (Ostrom, Gardner, and Walker, 1994). Findings indicate that successful network performance is related to such features as group size and stability (smaller and more stable clusters are, ceteris paribus, more successful), long-term perspectives, and levels of trust in the array (Ostrom, 1990, 211). Although Ostrom has little interest in public administration per se, this work offers insights into the kinds of circumstances in which more complex, networked patterns might deliver desired outputs over extended periods of time (for more direct ties to public administration, see Tang, 1991). 
Needs within Public Administration Specialties. Treating networks seriously also means reconsidering many other perspectives that have been brought to bear on the administrative task. Just as the specialty of organizational behavior, for example, has analyzed the microlevel behavioral dimensions of management, it is appropriate to consider how a microanalysis of network action might proceed. In particular, in what ways does this behavior depart from expectations derived from within-agency approaches?

Other specialties can also be informed by the proposition that networks should be treated seriously. Numerous research issues for human resource management are prompted by the network phenomenon. In a recent article, "The Network Society," Peter Drucker (1995) documents the continuing trend toward employment both in government and elsewhere of contractors, part-time employees, and temporaries. As Drucker notes (8), "relations between organizations themselves are changing ... fast. The most visible example is 'outsourcing,' in which a company, hospital, or government agency turns over an entire activity to an independent firm specializing in that kind of work." The theme, in effect, is the personnel management corollary of the "hollowing of the state." What happens to theories of work motivation where public managers find themselves supervising a changing cast of temporary or contract employees rather than career civil servants? How do managers build consensus and support in a literal government of strangers, to borrow Heclo's (1977) term originally coined for a much more limited stratum? What about managerial goals of representativeness and the building of a distinctive agency culture? ${ }^{3}$

For public budgeting and finance networked public administration raises new questions and requires theoretical reformulation. An obvious topic is theory regarding fiscal instruments such as contracting, loans and loan guarantees, debt, and in-kind exchanges. Most of these topics have made inroads in the literature, but solid theory remains scarce. Furthermore, ideas about how the structure of resource flows influences public management and decision-making are also needed (Porter, 1973; Provan and Milward, 1995).

\section{The Normative Agenda}

There is a need for scholarship on normative issues. Unfortunately, despite the crucial character of this subject, the present article can do no more than suggest that it be considered a central topic for future work.

Normative theory is a subject that has hardly been introduced into the networks dialogue as of yet. There is a double irony here. The field of ethical theory has devoted very little attention to organizational as opposed to individual ethical questions, so ethicists in public administration typically rely either on analyses designed for quite different settings than those facing public managers, or they must work from the few efforts aimed particularly at the bureaucratic context (Burke, 1986; Thompson, 1980).

Even the scarce work done on public-organizational settings may have limited bearing on the networked world of many public managers. Take the topic of diffusion of responsibility, a matter of concern for public-sector ethicists. Do networks catalyze tendencies for further diffusion, or do they encourage more responsible conduct and consciousness? What kinds of networks? Under what conditions? What can and should be the implications for public management? Basic issues of public interest, the role of the state, and ethical action as well as the norms to be used as assessment criteria may all have to be reconsidered. The issue is not so much whether the criteria and issues still apply. Rather, the very meanings of the normative standards are called into question. What does accountability amount to in thoroughly networked settings? Treating networks seriously compels a respecification of normative concepts and a reexamination of the fundamentals of public administrative ethics and politics.

\section{Implications for Research}

Some of the clearest ramifications for research can be highlighted as the following suggestions:

1. Undertake systematic research to explore the descriptive questions on the network agenda. How much of managers' time, effort, and contingencies lie in or are devoted to network contexts? Which kinds of managers, in which governments and policy fields? What shifts can be documented? What do managers actually do to deal with and seek influence within their network(s)?

2. Shift units and/or levels of analysis to the network. This suggestion could undergird any of several approaches. Research aimed at investigating programs, policy problems, or relatively stable clusters of organizations might be apropos, depending on the research question. Scholarship aimed at exploring administration at the intersection of related and well-defined policy fields is also likely to be productive.

3. Address both conceptual and theoretical agendas by identifying dimensions of network structure that may help to explain and mediate program and service delivery results. In particular, develop and test theoretical ideas that emphasize network features in explaining program or service delivery results. Do certain strategies and tactics of network management as practiced by public administrators seem to be related to successful results from the standpoint of the managers' responsibilities?

4. To concentrate emphasis on some highly networked contexts, devote attention to those policy problems that exhibit marked deviation from the stable and nearly decomposable issues forming the strongest justification for hierarchy. Examples of promising research targets include international programs, selfand community-organized efforts, and complex public-private initiatives.

5. Address perennial issues of normative theory with a sensitivity to the network theme. This suggestion includes considering how to translate some of the most enduring normative concepts into notions that have meaning in these larger arrays.

\section{Conclusion}

If the theses in this article are accepted-that networks are increasingly becoming important contexts for public administration and that networked settings are different in respects that matter for the conduct of administration - then the set of agendas outlined here must be considered salient. Public administration should attend to several types of network-focused research efforts, 
each aimed at addressing or redressing a void in scholarship. Each agenda implies sustained, creative, and systematic research. Each can help to craft the basis of a more-informed and realistic, albeit complex, public administration.

Laurence J. O'Toole, Jr., is a professor in the Department of Political Science and a research associate in the Institute of
Community and Area Development at the University of Georgia. He is author, coauthor, or editor of six books and many articles on public administration and public policy. His current research focuses primarily on issues of intergovernmental and interorganizational policy implementation, and he has contributed widely to studies on environmental policy and management.

\section{Acknowledgement}

An earlier version of this article was presented at the Public Affairs Workshop, Robert M. La Follette Institute of Public Affairs, the University of Wisconsin-Madison, 26 April 1995. Helpful comments by the workshop participants and the referees for PAR are gratefully acknowledged.

\section{Notes}

1. Public management and public administration are treated synonymously here.

2. Note, however, recent rigorous theoretical treatments demonstrating that hierarchies cannot be expected to reach stable, efficient production patterns even when the assumption of near decomposability holds (see Miller, 1992).

3. For a recent discussion of this set of issues, including some institutional implications for ill-structured policy problems, see Chisholm (1995).

4. Recently, the theme has become more prominent (Skok, 1995; LaPorte, 1996; Milward, 1996). It is to be hoped that these arguments for the importance of the network phenomenon for administration will be fol- lowed by additional practical and scholarly work.

5. Offe (1984) would say that networked interdependence emerges as tensions and contradictions develop in the broader political economy. Networks can be a way of trying to stitch together the rending social fabric.

6. Modeling human resource dynamics may be helpful, as well, to identify persistent channels of recruitment, mobility, and promotion as they develop and change in complex settings. For an attempt to employ vacancy chain analysis to identify such characteristics in a personnel context quite unlike that found for American public administration, see Urban (1989).

\section{References}

Agranoff, Robert (1991). "Human Services Integration: Past and Present Challenges in Public Administration." Public Administration Review 51 (November/December): 1-11.

Ansell, Christopher (1993). "French Workers between Parties and Units, 1872-1922." Ph.D. diss., University of Chicago.

Burke, John P. (1986). Bureaucratic Responsibility. Baltimore: Johns Hopkins University Press.

Chisholm, Donald (1995). "Problem Solving and Institutional Design." Journal of Public Administration Research and Theory 5 (October): 451491.

Cook, K. S. and J. M. Whitmeyer (1992). "Two Approaches to Social Structure: Exchange Theory and Network Analysis." Annual Review of Sociology 18: 109-127.

Dahl, Robert A. (1947). "The Science of Public Administration: Three Problems." Public Administration Review 7 winter: 1-11.

Dilulio, John J., Jr. and Donald F. Kettl (1995). Fine Print: The Contract with America, Devolution, and the Administrative Realities of American Federalism. Report 95-1, March. Washington, DC: Center for Public Management, Brookings Institution.

Drucker, Peter F. (1995). "The Network Society." The Wall Street Journal Europe. 30 March, 8.

Hanf, Kenneth I. (1994). The International Context of Environmental Management from the Negotiating Table to the Shop Floor. Breukelen, The Netherlands: Nijenrode University Press.

Heclo, Hugh (1977). A Government of Strangers. Washington, DC: Brookings Institution.

Hill, Larry B., ed. (1992). The State of Public Bureaucracy. Armonk, NY: M. E. Sharpe.

Horn, Murray J. (1995). The Political Economy of Public Administration: Institutional Choice in the Public Sector. New York: Cambridge University Press.

Hufen, Hans, and Arthur Ringeling (1990). Beleidsnetwerken. The Hague:
VUGA.

Hull, Chris, with Benny Hjern (1987). Helping Small Firms Grow. London: Croom Helm.

Kettl, Donald F. (1993). "Searching for Clues about Public Management: Slicing the Onion Different Ways." In Barry Bozeman, ed., Public Management: The State of the Art. San Francisco: Jossey-Bass, 55-68.

Knoke, D., and J. H. Kuklinski (1982). Network Analysis. Newbury Park, CA: Sage.

Koremenos, Barbara, and Laurence E. Lynn, Jr. (1996). "Leadership of a State Agency: An Analysis Using Game Theory." In Donald F. Kettl and H. Brinton Milward, eds., The State of Public Management. Baltimore: Johns Hopkins University Press, 213-240.

LaPorte, Todd R. (1996). "Shifting Vantage and Conceptual Puzzles in Understanding Public Organizational Networks." Journal of Public Administration Research and Theory, 6 (January), 49-74.

Levine, Charles H., B. Guy Peters, and Frank J. Thompson (1990). Public Administration: Challenges, Choices, Consequences. Glenview, IL: Scott, Foresman/Little, Brown.

Light, Paul C. (1995). Thickening Government: Federal Hierarchy and the Diffusion of Accountability. Washington, DC: Brookings Institution.

Lynn, Laurence E., Jr. (1993). "Policy Achievement as a Collective Good: A Strategic Perspective on Managing Social Programs." In Barry Bozeman, ed., Public Management: The State of the Art. San Francisco: Jossey-Bass, 108-133.

Mandell, Myrna P. (1990). "Network Management: Strategic Behavior in the Public Sector." In Robert W. Gage and Myrna P. Mandell, eds., Strategies for Managing Intergovernmental Policies and Networks. New York: Praeger, 29-53.

Maser, Steven M. (1986). "Transaction Costs in Public Administration." In Donald Calista, ed., Bureaucratic and Governmental Reform. Greenwich, CT: JAI, 55-72.

Mazmanian, Daniel, and Paul A. Sabatier (1990). Implementation and Public 
Policy. Rev. ed. Washington, DC: University Press of America.

Miller, Gary J. (1992). Managerial Dilemmas: The Political Economy of Hierarchy. Cambridge: Cambridge University Press.

Milward, H. Brinton, ed. (1996). Symposium on "The Hollow State: Capacity, Control and Performance in Interorganizational Settings." Journal of Public Administration Research and Theory 6 (April): 193-313.

Milward, H. Brinton and Keith G. Provan (1993). "The Hollow State: Private Provision of Public Services." In Helen Ingram and S. R. Smith, eds., Public Policy for Democracy. Washington, DC: Brookings Institution, 222-237.

Offe, Claus (1984). Contradictions of the Welfare State. John Keane, ed. London: Hutchinson.

Osborne, David, and Ted Gaebler (1992). Reinventing Government: How the Entrepreneurial Spirit is Transforming the Public Sector. Reading, MA: Addison-Wesley.

Ostrom, Elinor (1990). Governing the Commons. Cambridge: Cambridge University Press.

Ostrom, Elinor, Roy Gardner, and James Walker (1994). Rules, Games, and Common-Pool Resources. Ann Arbor: University of Michigan Press.

O’Toole, Laurence J., Jr. (1993). "Multiorganizational Policy Implementation: Some Limitations and Possibilities for Rational Choice Contributions." In Fritz W. Scharpf, ed., Games in Hierarchies and Networks. Frankfurt am Main/Boulder, CO: Campus Verlag/Westview, 1-39. , (1995). "Rational Choice and Policy Implementation: Implications for Interorganizational Network Management." American Review of Public Administration 25 (March): 43-57.

Pappi, Franz Urban, David Knoke, and Susanne Bisson (1993). "Information Exchange in Policy Networks." In Fritz W. Scharpf, ed., Games in Hierarchies and Networks. Frankfurt am Main/Boulder, CO: Campus Verlag/Westview, 287-313.

Parks, Roger B. (1985). "Metropolitan Structure and Systemic Performance: The Case of Police Service Delivery." In Kenneth I. Hanf and Theo A. J. Toonen, eds., Policy and Implementation in Federal and Unitary Systems. Dordrecht: Martinus Nijhoff, 161-191.
Porter, David O. (1973). The Politics of Budgeting Federal Aid: Resource Mobilization by Local School Districts. Beverly Hills, CA: Sage.

Pressman, Jeffrey, and Aaron Wildavsky (1984). Implementation. 3rd ed. Berkeley: University of California Press.

Provan, Keith G., and H. Brinton Milward (1995). "A Preliminary Theory of Network Effectiveness: A Comparative Study of Four Mental Health Systems." Administrative Science Quarterly 40 (March): 1-33.

Rittel, Horst W. J., and Melvin Webber (1973). "Dilemmas in a General Theory of Planning." Policy Sciences 4 (June): 155-169.

Scharpf, Fritz W. (1977). "Public Organization and the Waning of the Welfare State: A Research Perspective." European Journal of Political Research 5: 239-278.

Simon, Herbert A. (1976). Administrative Behavior. 3rd ed. New York: Free Press.

Skok, James E. (1995). "Policy Issue Networks and the Public Policy Cycle: A Structural-Functional Framework for Public Administration." Public Administration Review 55 (July-August): 325-332.

Stoker, Robert (1991). Reluctant Partners. Pittsburgh, PA: University of Pittsburgh Press.

Tang, Shui Yan (1991). "Institutional Arrangements and the Management of Common-Pool Resources." Public Administration Review 51 (JanuaryFebruary): 42-51.

Thompson, Dennis F. (1980). "Moral Responsibility of Public Officials: The Problem of Many Hands." American Political Science Review 74 (December): 905-916.

Thompson, Fred (1993). "Matching Responsibilities with Tactics: Administrative Controls and Modern Government." Public Administration Review 53 (July-August): 303-318.

Urban, Michael (1989). An Algebra of Soviet Power: Elite Circulation in the Belorussian Republic, 1966-86. Cambridge: Cambridge University Press.

Wamsley, Gary L., Robert N. Bacher, Charles T. Goodsell, Philip S. Kronenberg, John A. Rohr, Camilla M. Stivers, Orion F. White, and James F. Wolf (1990). Refounding Public Administration. Newbury Park, CA: Sage. 